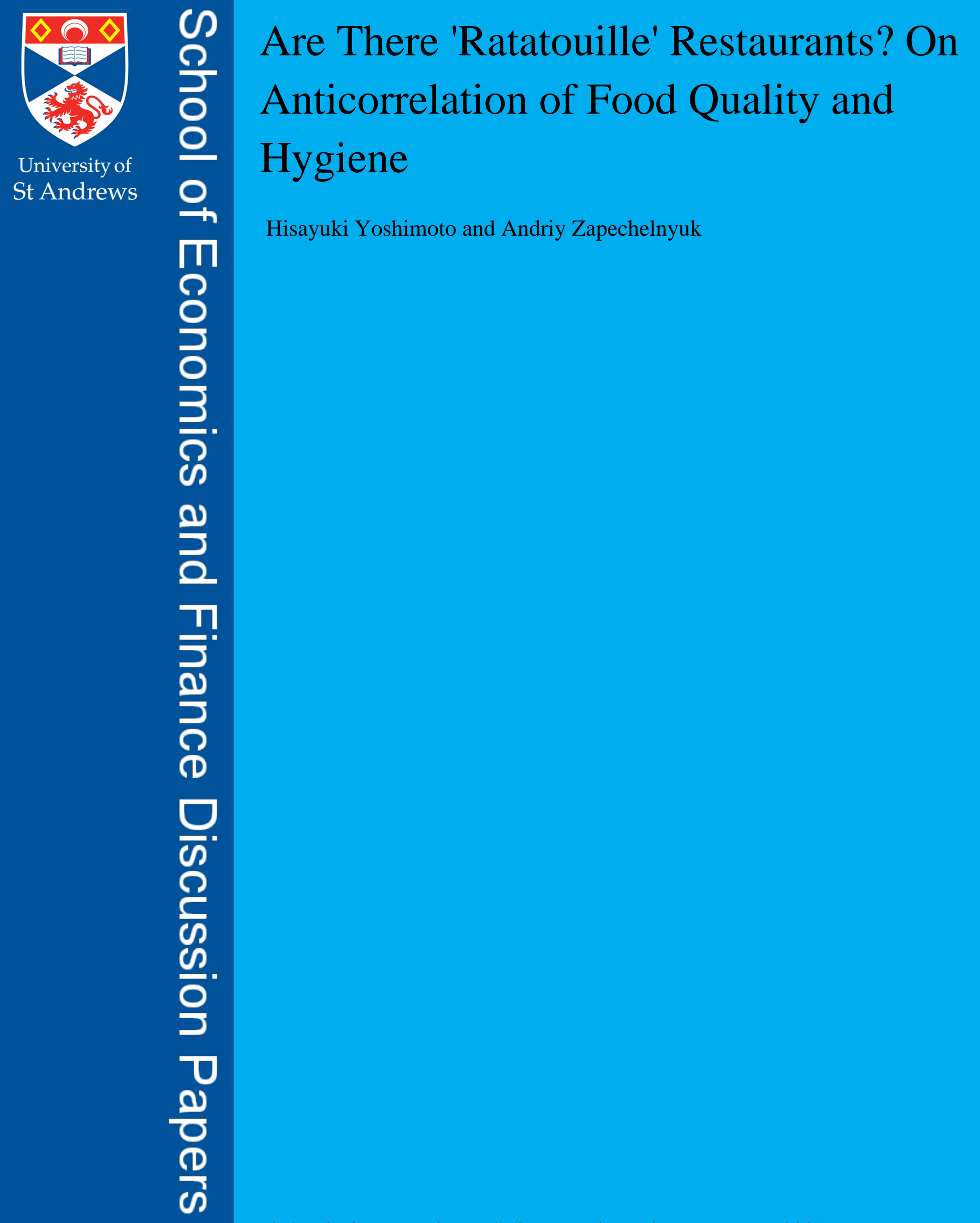

School of Economics and Finance Discussion Paper No. 2001 19 Dec 2019 (revised 5 Mar 2020) JEL Classification: H75, L15, D22, I18

Keywords: Food quality, restaurants, reviews, hygiene standards, food hygiene certification 


\title{
ARE THERE "RATATOUILLE" RESTAURANTS? ON ANTICORRELATION OF FOOD QUALITY AND HYGIENE
}

\author{
Hisayuki Yoshimoto AND ANDRIY Zapechelnyuk
}

\begin{abstract}
We study the empirical relationship between hygiene conditions in restaurants and their food quality rated by professional reviewers. Using evidence from the UK, we show that this relationship is negative and statistically significant. So, a higher food quality rating is generally associated with a less sanitary kitchen. We find that $3 \%$ of Michelin starred restaurants in our dataset have poor hygiene conditions, while the same is true for only $2 \%$ of non-Michelin starred restaurants. Our findings illuminate potential channels through which the anticorrelation between food quality and hygiene could be mitigated, which can be helpful for hygiene inspection design.
\end{abstract}

JEL Classification: L15, H75, D22, I18

Keywords: Food quality, restaurants, reviews, hygiene standards, food hygiene certification

Date: 5th March 2020

Yoshimoto: Adam Smith Business School, University of Glasgow, University Avenue, Glasgow G12 8QQ, UK. E-mail: Hisayuki.Yoshimoto@glasgow.ac.uk.

Zapechelnyuk: School of Economics and Finance, University of St Andrews, Castlecliffe, the Scores, St Andrews KY16 9AR, UK. E-mail: az48@st-andrews.ac.uk.

The authors thank Toman Barsbai, Dakshina De Silva, David Jaeger, Margaret Leighton, Marco Manacorda, and Arjunan Subramanian for helpful comments and suggestions. Financial support from the Economic and Social Research Council Grant ES/N01829X/1 is gratefully acknowledged. 
The paper is currently undergoing a substantial revision.

Please come back later for the updated version, or email to az48@st-andrews.ac.uk to check the status of the revision or to request the most recent update. 